14.11

\title{
Воздействие слабого статического магнитного поля и олигопептидов на клеточную пролиферацию и когнитивные функции организмов различных видов
}

\author{
(C) Е.С. Заломаева, ${ }^{1,2}$ П.Н. Иванова, ${ }^{1,2}$ Н.И. Чалисова, ${ }^{1}$ С.В. Сурма, ${ }^{1}$ Е.В. Токмачева, ${ }^{1}$ \\ Е.В. Савватеева-Попова, ${ }^{1}$ Б.Ф. Щеголев, ${ }^{1}$ Е.А. Никитина ${ }^{1,2}$ \\ ${ }^{1}$ Институт ффизиологии им. И.П. Павлова РАН, \\ 199034 Санкт-Петербург, Россия \\ ${ }^{2}$ Российский государственный педагогический университет им. А.И. Герцена, \\ 191186 Санкт-Петербург, Россия \\ e-mail: 21074@mail.ru
}

Поступило в Редакцию 12 декабря 2019 г.

В окончательной редакции 16 февраля 2020 г.

Принято к публикации 17 февраля 2020 г.

Изучено воздействие на организм двух стрессорных факторов - слабого статического магнитного поля (ССМП) с величиной индукции $200 \mu$ Т и ряда эпигенетических регуляторов, олигопептидов. Результаты опытов с воздействием тканеспецифических олигопептидов оказались сопоставимы с результатами воздействия ССМП. Анализ результатов экспериментов по изучению когнитивного поведения привел к выводу о благоприятном воздействии на формирование среднесрочной памяти при использовании олигопептидов AlaGlu-Asp-Pro и Lys-Glu-Asp-Ala. Отмечено, что эффективность действия внешних CCMП на биологические объекты обусловлена их высокой проникающей способностью в биологические среды.

Ключевые слова: воздействие стресса, магнитное поле, пептиды, ткани различного генеза, среднесрочная память.

DOI: 10.21883/JTF.2020.10.49796.400-19

\section{Введение}

Актуальной проблемой современной нейрофизиологии и медицины является изучение механизмов возникновения социально-значимых болезней, в том числе нейродегенеративных, кардиоваскулярных, раковых, инфекционных заболеваний, которые являются результатом сложного взаимодействия неблагоприятных внешних факторов и индивидуальных особенностей генома, предрасполагающих к развитию болезни. Среди факторов, провоцирующих возникновение подобных заболеваний, большое значение имеют различные стрессорные воздействия.

Одним из наименее изученных стрессорных факторов, которые способны оказывать заметное воздействие на живые организмы, в том числе и человека, является статическое магнитное поле низкой интенсивности до $300 \mu \mathrm{T}$. Ранее считалось, что магнитные поля с индукцией до $30 \mathrm{mT}$ безопасны для человека. Однако за последние годы накопился большой массив данных, демонстрирующий потенциальную опасность таких полей. Всемирная организация здравоохранения (ВО3) в 2002 г. признала, что долговременное воздействие магнитного поля с величиной индукции $300 \mathrm{nT}$ и более „обладает возможным канцерогенным эффектом по отношению к людям“ [1]. Помимо канцерогенной опасности, слабое статическое магнитное поле (ССМП) до $300 \mu \mathrm{T}$ способно оказывать влияние на работу многих систем организ- ма, в первую очередь нервной, сердечно-сосудистой и половой.

Статическое магнитное поле Земли существовало на всех этапах эволюционного развития живых организмов, оказывая на них влияние при его изменениях. В последнее время для магнитного поля Земли отмечено значительное смещение магнитных полюсов, при этом скорость такого смещения увеличилась с $15 \mathrm{~km} / \mathrm{year}$ в 2000 г. до $55 \mathrm{~km} /$ year в 2019 г., что в настоящей работе не учитывалось. Магнитное поле (МП) Земли не является однородным, есть участки с повышенным уровнем геомагнитного фона, в частности, Курская магнитная аномалия с величиной индукции МП 200 $\mu \mathrm{T}$, участки горных пород и прибрежные зоны, в которых наблюдается значительное содержание соединений железа (магнитные пески Уреки), а есть область, называемая южно-атлантической аномалией, которая простирается от Чили в Южной Америке до Зимбабве в Южной Африке, со слабым магнитным полем [2,3]. На широте Санкт-Петербурга величина индукции МП Земли составляет $\sim 50 \mu \mathrm{T}$. Меняющееся МП Земли вместе с возрастающим техногенным магнитным загрязнением делает актуальной задачу изучения воздействия слабых статических магнитных полей на организмы различных видов. В предыдущих работах авторов было продемонстрировано воздействие ССМП на биологических моделях разного уровня организации [4-6]. 
Все живые организмы находятся в непрерывном взаимодействии с внешней средой. Если те или иные факторы среды выходят за пределы физиологической нормы, это может вызвать состояние физиологического стресса, характеризующееся модификацией метаболизма и сбоем в функционировании генома. Такие факторы могут иметь как физическую природу (например, воздействие ССМП), так и химическую. К подобным химическим факторам могу быть отнесены и эпигенетические регуляторы [7], способные одновременно вовлекать в ответную реакцию значительное число генов, в том числе и те гены, от которых зависят гуморальные защитные системы организма. Такими регуляторами являются и короткие пептиды, эпигенетически воздействующие на геном и получившие наименование „цитогены“. Обнаруженные в геноме под влиянием регуляторных пептидов сдвиги носят эпигенетический характер, ибо эти изменения не связаны с нарушением структуры ДНК. Поэтому актуальной задачей является комплексное исследование действия ССМП и биорегуляторных олигопептидов на различные аспекты функционирования организмов различных видов.

В настоящей работе изучено воздействие ССМП и олигопептидов на такие универсальные процессы, как морфологические характеристики различных тканей млекопитающих (крыс) и физиологические когнитивные функции насекомых (дрозофилы).

\section{1. Методы исследования}

\section{1. Исследование клеточной пролиферации}

Органотипическое культивирование фрагментов тканей экспериментальных животных является наиболее адекватным и удобным методом быстрой количественной оценки влияния исследуемых воздействий на клеточном уровне. Это связано с тем, что изменение количества клеток является результатом стимуляции или ингибирования клеточной пролиферации и служит критерием первичной интегральной оценки биологической активности воздействий на ткани организма. Органотипическое культивирование тканей проведено на крысах линии Вистар из биоколлекции „Коллекция лабораторных млекопитающих разной таксономической принадлежности“ ФБГУН Института физиологии им. И.П. Павлова РАН. Животных затравливали путем вдыхания паров эфира с соблюдением этических стандартов. В экспериментах использовано 750 эксплантатов тканей коры головного мозга, селезенки, печени, которые по описанной ранее методике органотипического культивирования $[8,9]$ помещались в чашки Петри. Фрагменты коры головного мозга разделяли на эксплантаты величиной около $1 \mathrm{~mm}^{3}$, помещали в количестве 20 в каждую из чашек Петри с полилизиновым покрытием дна, заливали $3 \mathrm{ml}$ питательной среды. Питательная среда с $\mathrm{pH} 7.2$ имела состав: 35\% раствора Хенкса, 35\% среды Игла, 25\% сыворотки крови плодов коровы, глюкоза (60 mg\%), инсулин (0.5 unit $/ \mathrm{ml})$, гентамицин (100 unit $/ \mathrm{ml})$. Чашки Петри помещали в $\mathrm{CO}_{2}$-инкубатор при $36.8^{\circ} \mathrm{C}$ и воздействии ССМП. Контрольные чашки не подвергали действию ССМП. Величина индукции магнитного поля в термостате до расположения в нем чашек Петри с эксплантатами и постоянного магнита составляла $19 \mu \mathrm{T}$. ССМП формировали постоянным магнитом кольцеобразной формы с диаметром $12 \mathrm{~mm}$ и толщиной $3 \mathrm{~mm}$. Постоянный магнит находился снизу подложки, выполненной из немагнитного материала, сверху которой располагалась чашка Петри с эксплантатом. Величина индукции магнитного поля в зоне расположения исследуемой культуры тканей составляла $200 \mu$ Т. Измерение индукции магнитного поля в зоне расположения чашки Петри осуществляли отечественным трехкомпонентным магнитометром НВ0305.2А на основе датчиков Холла с диапазонами измерений 10 и $100 \mathrm{mT}$.

В другой серии опытов без воздействия ССМП в экспериментальные чашки Петри вводили синтезированные олигопептиды. На кору головного мозга действовал тетрапептид Ala-Glu-Asp-Pro, на печень трипептид LysGlu-Asp, на селезенку дипептид Lys-Glu. При раститровке определяли эффективные концентрации пептидов, которые составляли $0.05 \mathrm{ng} / \mathrm{ml}$.

Через 3 суток определяли индекс площади (ИП), как отношение площади эксплантата вместе с зоной роста к исходной площади. Статистическую обработку данных проводили с использованием программы „Statistica 6.0“. Для каждой ткани обработаны данные двух экспериментов (количество выборки $n=20$ ) с расчетом средних величин (ошибка среднего $p \pm 0.8$ ).

\section{2. Оценка способности к обучению и формированию среднесрочной памяти у дрозофилы}

Работа проведена на животных из биоколлекции ФБГУН Института физиологии им. И.П. Павлова РАН. В качестве материала исследования были использованы следующие линии Drosophila melanogaster: Canton-S $(C S)$ - контрольная линия дикого типа; cardinal $(c d)$ содержит мутацию $c d$ (3-75.7; ярко-красный цвет глаз), нарушающую синтез фермента феноксазинонсинтетазы, что приводит к накоплению 3-гидроксикинуренина, вызывающего оксидативный стресс и нейродегенерацию. Линия характеризуется нарушением формирования среднесрочной памяти при действии теплового шока (ТШ).

Мух выращивали в стаканчиках объемом $160 \mathrm{ml}$ на стандартной изюмно-дрожжевой среде при $+25 \pm 0.5^{\circ} \mathrm{C}$, $60 \%$ влажности и свето-темновом цикле $12: 12 \mathrm{~h}$. Вылупившихся насекомых без наркотизации сортировали по полу. Отбирали самцов анализируемой линии и помещали поодиночке в стаканчики со средой. В качестве объектов ухаживания для самцов анализируемых линий использовали оплодотворенных за сутки до опыта самок линии Canton-S. Обучение и тестирование проводили в экспериментальных камерах из оргстекла (диаметр - 
$15 \mathrm{~mm}$, высота - $5 \mathrm{~mm})$. Исследования проводили на взрослых мухах в возрасте 5 суток при температуре $25 \pm 0.5^{\circ} \mathrm{C}$ в первой половине дня.

Воздействие тепловым шоком (ТШ) проводили по схеме, разработанной в лаборатории нейрогенетики ФБГУН Института физиологии им. И.П. Павлова РАН [10]. Тепловое воздействие на стадии имаго самцов $C S$ и $c d$ осуществляли в водяном термостате GFL 1086 (GFL, Германия) при температуре $+37^{\circ} \mathrm{C}$ в течение $30 \mathrm{~min}$ за $1 \mathrm{~h}$ до эксперимента. В качестве контроля использовали интактных животных (без ТШ).

Исследовали влияние на способность к обучению и формированию среднесрочной памяти тетрапептида Ala-Glu-Asp-Pro и тетрапептида Lys-Glu-Asp-Ala. Концентрация пептидов во всех случаях составляла $15 \mu \mathrm{g} / 1$. Пептиды добавляли в среду, в которой развивались личинки дрозофил. Имаго пересаживали на среду без пептида и выдерживали 5 суток.

Для оценки способности к обучению и формированию среднесрочной памяти использовали метод условно-рефлекторного подавления ухаживания (УРПУ). При ухаживании самца за оплодотворенной самкой сочетаются два безусловных стимула - аттрактивный (стимулирующий ухаживание феромон-афродизиак) и аверсивный (подавляющий ухаживание феромон-антиафродизиак). Антиафродизиаком обладают только оплодотворенные самки и высвобождают его в ответ на ухаживание самца. В результате сочетания аттрактивный стимул становится аверсивным условным стимулом, что снижает его аттрактивные свойства. Степень аттрактивности или аверсивности стимула определяется по таким реакциям животного, как приближение к стимулу или удаление от него. Для выработки УРПУ (тренировки) пятисуточного самца тестируемой линии, не имеющего опыта полового поведения, помещали в экспериментальную камеру вместе с оплодотворенной пятисуточной самкой Canton-S на $30 \mathrm{~min}$. При оценке способности к обучению применяли немедленный тест после тренировки. Формирование среднесрочной памяти тестировали через $3 \mathrm{~h}$ (180 min) после тренировки. В качестве контроля использовали самцов, не имеющих опыта полового поведения. Этограмму поведения самца регистрировали в течение $300 \mathrm{~s}$, фиксируя время начала отдельных элементов ухаживания (ориентация и преследование, вибрация, лизание, попытка копуляции), а также время исполнения элементов, не связанных с ухаживанием (активность (побежка), прининг, покой). В каждой группе тестировали не менее 20 пар мух. Для каждого самца вычисляли индекс ухаживания $(C I)$, т.е. время ухаживания самца за самкой, выраженное в процентах от общего времени наблюдения. Для количественной оценки результатов обучения вычисляли индекс обучения $(L I)$ по следующей формуле:

$L I=\left[\left(C I_{I}-C I_{T}\right) / C I_{I}\right] \times 100 \%=\left(1-C I_{T} / C I_{I}\right) \cdot 100 \%$,

где $C I_{I}$ и $C I_{T}-$ средние индексы ухаживания для независимых выборок самцов, не имеющих опыта по- лового поведения, и самцов, прошедших тренировку, соответственно [11].

\section{2. Результаты и обсуждение}

\section{1. Влияние ССМП и олигопептидов на клеточную пролиферацию}

Полученные с использованием метода органотипического культивирования тканей данные показывают, что при воздействии ССМП с индукцией $200 \mu \mathrm{T}$ на ткани эктодермального генеза - коре головного мозга - клеточная пролиферация увеличивалась на $30 \pm 3 \%(n=12, p<0.05)$, по сравнению с контролем $(n=14)$ (рис. 1). В селезенке - ткани мезодермального генеза - пролиферационный процесс увеличивался на $17 \pm 1 \%(n=12, p<0.05)$, по сравнению с контролем $(n=14)$ (рис. 2). В печени - ткани энтодермального генеза - пролиферационный процесс увеличивался на $17 \pm 1 \%(n=15, p<0.05)$ по сравнению с контролем $(n=13)$ (рис. 3$)$.

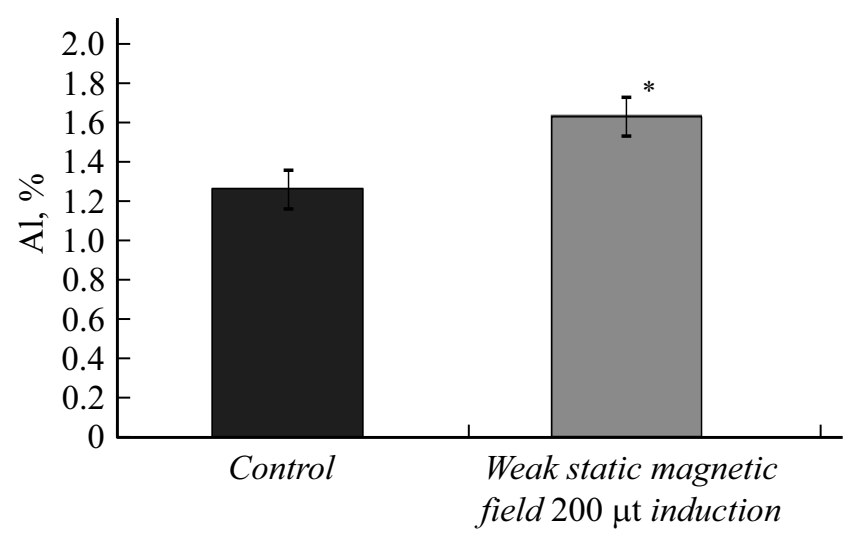

Рис. 1. Изменение индекса площади (AI) эксплантатов коры головного мозга по отношению к контролю при воздействии ССМП с индукцией $200 \mu \mathrm{T} .{ }^{*} p<0.05$ по сравнению с контролем

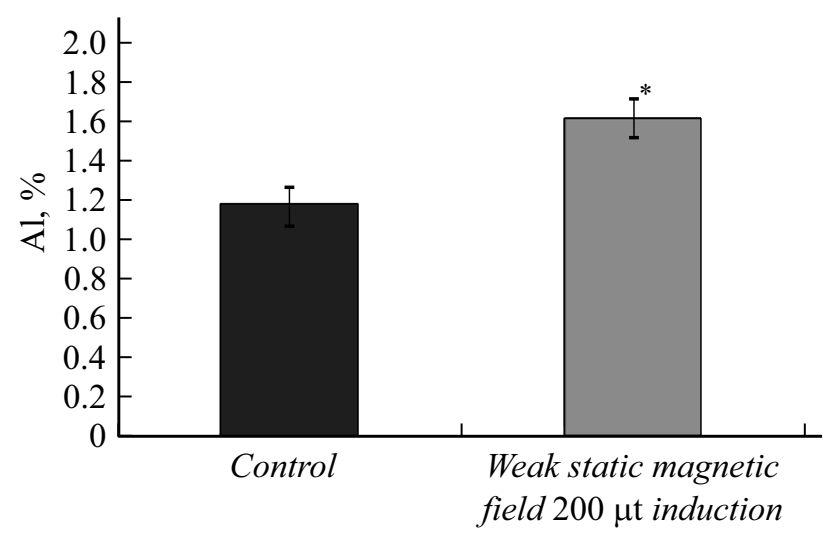

Рис. 2. Изменение индекса площади (AI) эксплантатов селезенки по отношению к контролю при воздействии ССМП с индукцией $200 \mu \mathrm{T}$. ${ }^{*} p<0.05$ по сравнению с контролем. 


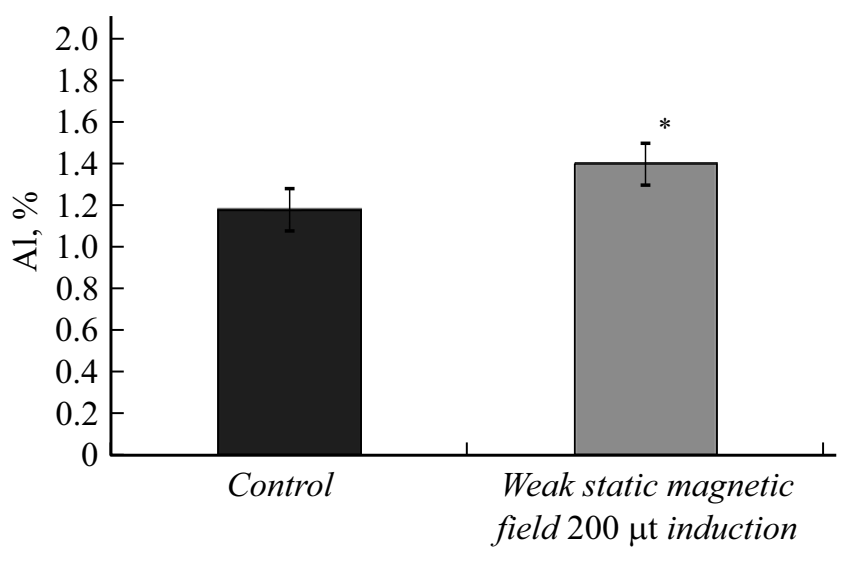

Рис. 3. Изменение индекса площади (AI) эксплантатов печени по отношению к контролю при воздействии ССМП с индукцией $200 \mu \mathrm{T}^{*} p<0.05$ по сравнению с контролем.

Индекс площади (АI\%) при действии олигопептидов на эксплантаты в органотипической культуре ткани

\begin{tabular}{c|c|c|c}
\hline Олигопептид & Кора головного мозга & Печень & Селезенка \\
\hline $\begin{array}{c}\text { Тетрапептид } \\
\text { Трипептид } \\
\text { Дипептид }\end{array}$ & $32 \pm 3^{*}$ & $18 \pm 1^{*}$ & \\
& & & $39 \pm 5^{*}$
\end{tabular}

При ме чание . * $p<0.05$ по сравнению с контролем.

Таким образом, один из основных клеточных процессов - пролиферация - происходит при действии ССМП в тканях различного генеза (происходящих из какого- либо одного из зародышевых листков) с различной интенсивностью. Наибольший эффект воздействия ССМП наблюдается в ткани эктодермального генеза коре головного мозга. Следует отметить, что ткани эктодермального генеза (нервная ткань, кожа) развиваются в онтогенезе в первую очередь, в то время как ткани энтодермального генеза (печень) развиваются в позднем зародышевом периоде. Можно полагать, что именно в связи с этими временными интервалами клеточная пролиферация в печени была ниже по сравнению как с тканями эктодермального (нервная ткань), так и мезодермального (селезенка) генеза. Ткань селезенки обладает бо́льшим пролиферационным потенциалом, в ней происходит постоянный процесс клеточного обновления, и в условиях действия ССМП этот процесс, как показано при культивировании данной ткани, значительно ускоряется. В наших предыдущих работах $[8,9,12]$ было показано, что при усилении клеточной пролиферации происходит снижение другого основного клеточного процесса - поптоза (запрограммированной клеточной гибели). Поэтому выявленный стимулирующий клеточную пролиферацию эффект воздействия ССМП создает базу для дальнейшей разработки на этой основе аппаратуры, предназначенной для усиления регенерации различных тканей организма при патологиях.
Результаты второй серии опытов с воздействием тканеспецифических олигопептидов (см. таблицу) оказались сопоставимы с результатами воздействия ССМП на ткани. ИП экспериментальных эксплантатов коры головного мозга увеличивался при действии тетрапептида Ala-Glu-Asp-Pro на $32 \pm 3 \% \quad(n=15, p<0.05)$, Lys-Glu-Asp ИП ткани селезенки на $39 \pm 5 \%(n=13$, $p<0.05)$, Lys-Glu ткани печени на $18 \pm 1 \% \quad(n=15$, $p<0.05)$, по сравнению с контролем $(n=14,15,14 \mathrm{KD}$ соответственно).

Таким образом, можно говорить об однонаправленности изменения клеточной пролиферации в различных тканях под влиянием как ССМП, так и биорегуляторных пептидов. Это факт может свидетельствовать о возможно одинаковых эпигенетических механизмах воздействия ССМП и олигопептидов, что, несомненно, требует дальнейшего изучения.

Такой вывод особенно важен потому, что извечные вопросы о роли наследственности и среды в определении таких сложных полигенных признаков, как поведение, особенности условно-рефлекторной деятельности и старение определяются ,эпигенетическим форматированием“ участвующих в этих процессах генов, т.е. зависимым от возраста изменением экспрессии генов без изменения их первичной последовательности. Идентификация регулируемых в пространстве и времени эпигенетических модификаций генетических локусов при сохранении памяти обнаруживает важные свойства природы эпигенетической регуляции: ее развитие по принципу „стимул-ответ“, мишень-специфическое и долговременное действие, однако механизмы этих процессов остаются во многом неизвестными [13].

\section{2. Влияние олигопептидов на способность к обучению и формирование среднесрочной памяти}

Вопрос о связи между организацией генома и когнитивными нарушениями требует поиска моделей, позволяющих одновременно исследовать все эти аспекты. Такую возможность дает дрозофила, мутантные линии которой можно использовать не только для моделирования нейродегенеративных заболеваний, но и для изучения на уровне поведения целого организма последствий событий в динамической пространственной организации ядра. Одной из причин возникновения нейродегенеративных изменений в мозге является нарушение кинуренинового пути обмена триптофана (КПОТ). Некоторые его метаболиты, в частности, 3-гидроксикинуренин (3-НОК), в клеточных культурах нейронов индуцируют процессы свободнорадикального окисления, вызывающие гибель клеток. Окислительный стресс играет важную роль в генезе различных патологических состояний, таких как ишемия-реперфузия, атеросклероз, сердечная недостаточность, гипертензия, почечная недостаточность, кардиомиопатия, гипертония, болезнь Альцгеймера, болезнь Паркинсона, диабет; он также является одной из 


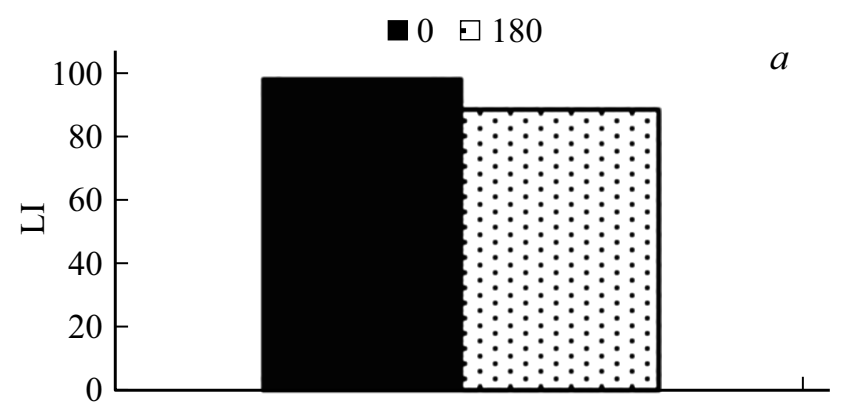

Time, $\min$

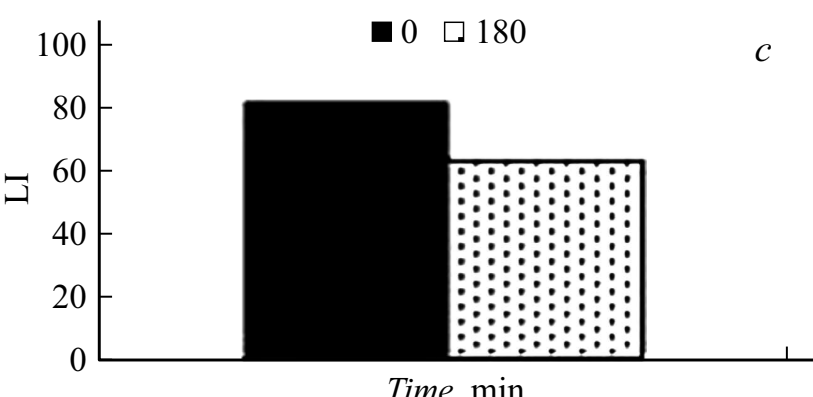

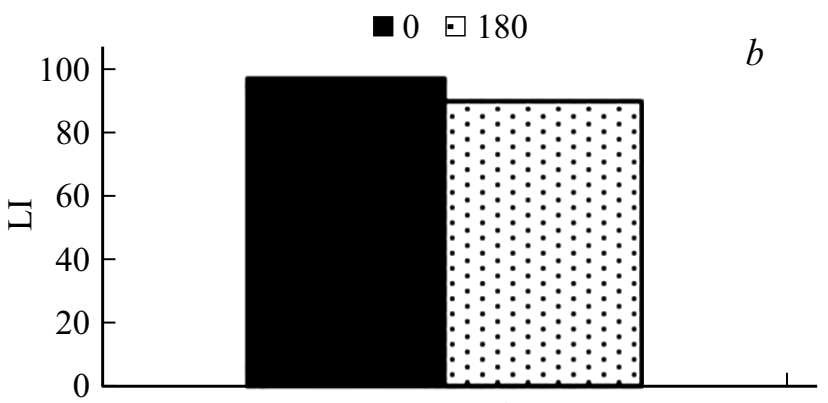

Time, $\min$

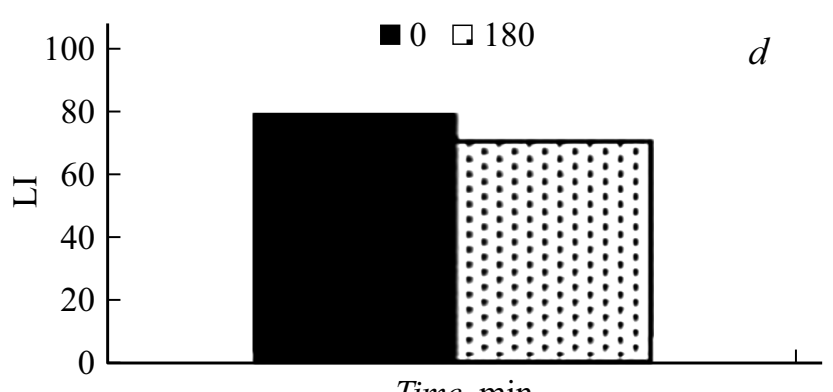

Time, min

Рис. 4. Динамика сохранения условно-рефлекторного подавления ухаживания при тестировании обучения и среднесрочной памяти у линии CS Drosophila melanogaster. $a$ - тетрапептид Ala-Glu-Asp-Pro, $25^{\circ} \mathrm{C}, b$ - тетрапептид Ala-Glu-Asp-Pro, $37^{\circ} \mathrm{C}, c-$ тетрапептид Lys-Glu-Asp-Ala, $25^{\circ} \mathrm{C}, d-$ тетрапептид Lys-Glu-Asp-Ala, $37^{\circ} \mathrm{C}$. По оси абсцисс: время (min); по оси ординат: LI - индекс обучения, а.u. Темные столбики - тест сразу после тренировки, светлые столбики - тест через $3 \mathrm{~h}$ после тренировки.

$\square 180$

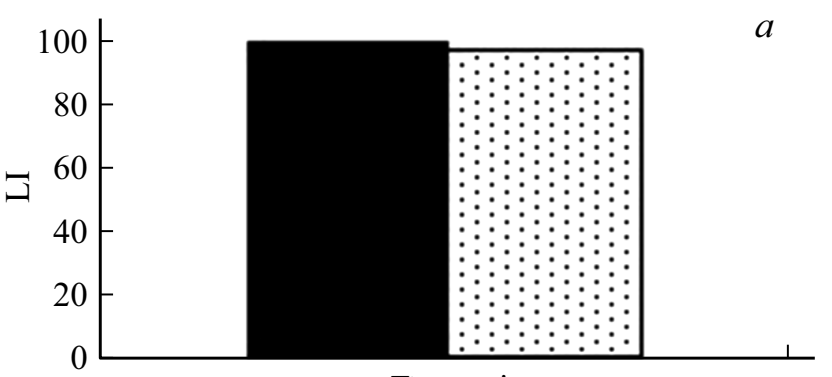

Time, $\min$

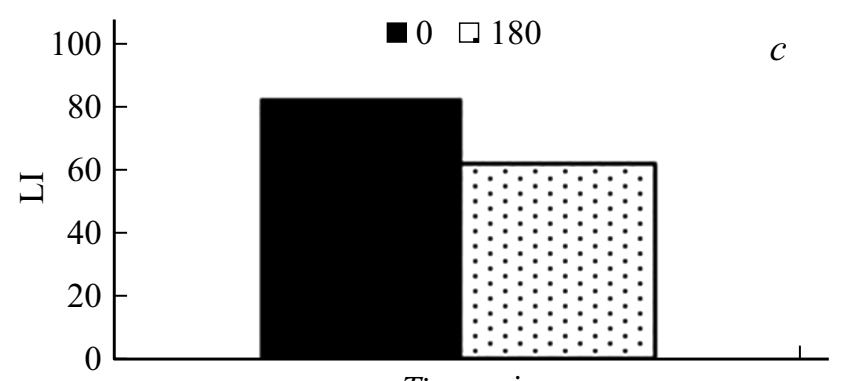

Time, $\min$
$0 \quad \square 180$
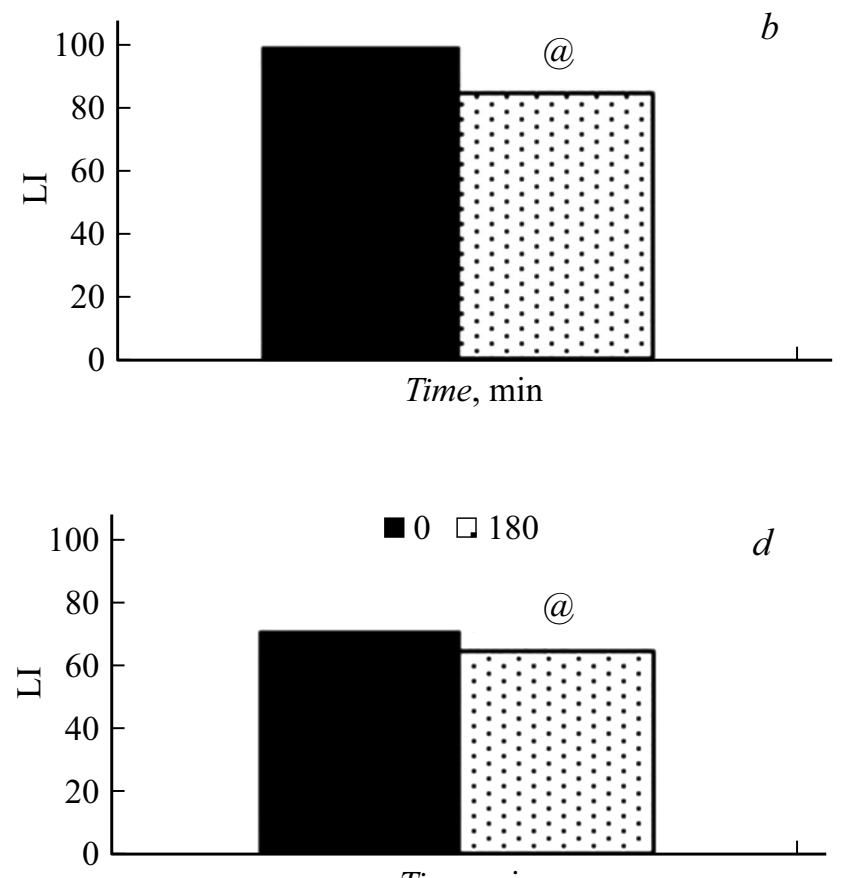

Time, $\min$

Рис. 5. То же, что рис. 4, для линии cd Drosophila melanogaster. - индекс обучения достоверно отличается от варианта без воздействия препарата (двусторонний тест рандомизации, $p<0.05$ ).

составляющих процесса старения [14]. Концепция роли окислительного стресса в патохимических механизмах нейронального повреждения при нейродегенеративных заболеваниях определяет один из путей их терапии с использованием различных биологических молекул, в том числе олигопептидов. 
Нами исследовано влияние тетрапептидов $\mathrm{Ala}-\mathrm{Glu}-$ Asp-Pro и Lys-Glu-Asp-Ala на обучение и формирование среднесрочной памяти линий CS и cd при нормальной температуре $\left(25^{\circ} \mathrm{C}\right)$ и после теплового шока $\left(37^{\circ} \mathrm{C}\right)$. Добавление изучаемых тетрапептидов в корм мухам линии дикого типа CS не приводило к изменениям формирования среднесрочной памяти (рис. 4).

При добавлении в корм тетрапептида Ala-Glu-AspPro и тетрапептида Lys-Glu-Asp-Ala у мутанта $c d$ в интактном контроле были выявлены нарушения формирования среднесрочной памяти (рис. 5). Однако при ТШ применение данных олигопептидов привело к достоверному улучшению среднесрочной памяти.

Анализ полученных результатов приводит к выводу о благоприятном воздействии на формирование среднесрочной памяти у мутантов $c d$ при использовании исследуемых олигопептидов.

В ряде предыдущих работ $[15,16]$ были получены данные, свидетельствующие о том, что олигопептиды способны стимулирующим образом влиять как на клеточную пролиферацию в подкорковых структурах головного мозга млекопитающих (крыс), так и на функцию высших отделов центральной нервной системы, ответственных за когнитивную деятельность, у насекомых (пчел).

Схожесть в конечном результате воздействия слабых статических магнитных полей и биорегуляторных пептидов у разных видов животных на пролиферативную активность клеток в культуре нервной ткани и на когнитивную деятельность позволяет предположить существование общего древнего механизма регуляции жизнедеятельности организмов.

\section{Заключение}

Полученные нами данные подтверждают показанный ранее на клеточном уровне [17] эффект воздействия ССМП, повышенного относительно МП Земли $(\sim 50 \mu \mathrm{T}$ в Санкт-Петербурге), когда было обнаружено, что ССМП в диапазоне $60(-) 160 \mu \mathrm{T}$ стимулирует пролиферацию и дифференцировку сателлитных мышечных клеток в культуре, повышая скорость формирования многоядерных утолщенных миотрубок и нарастание внутриклеточной концентрации кальция $\left[\mathrm{Ca}^{2+}\right]$.

Наблюдаемое при воздействии ССМП изменение клеточной пролиферации может быть связано с множественными нарушениями работы различных клеточных сигнальных каскадов, которые регулируют экспрессию генов не только посредством активации эффекторных молекул, но и прямо воздействуя на генетический аппарат. Возможно, этим объясняется согласованность биохимических каскадов в процессах адаптации в ответ на стрессорные воздействия $[6,18]$, сопровождающие эти процессы. Ранее в работе академика А.Л. Бучаченко [19] была показана ядерно-магнитная зависимость ферментативного синтеза ДНК, которая может лежать в основе регенерационных процессов, выявленных в нашей работе. Под влиянием ССМП усиливается синтез ДНК, что приводит к ускорению митоза и увеличению количества регенерирующих клеток.

Выявленный наибольший эффект воздействия ССМП в коре головного мозга согласуется с представлениями о том, что действие магнитного поля на нервную систему характеризуется изменением поведения организма, его условно-рефлекторной деятельности, физиологических процессов за счет стимуляции процессов торможения. Реакция организма на воздействие магнитного поля во многом зависит от исходного функционального состояния, и в первую очередь - от состояния нервной системы.

Полученные данные показывают, что эффективность действия внешних слабых статических магнитных полей на биологические объекты обусловлена не столько их интенсивностью, сколько их высокой проникающей способностью в биологические среды, и вследствие этого способностью ускорять процессы регенерации в тканях различного генеза, что создает основу для их применения в практической медицине.

\section{Финансирование работы}

Работа выполнена при финансовой поддержке Программы фундаментальных научных исследований государственных академий на 2013-2020 гг. (ГП-14, раздел 63).

\section{Соблюдение этических стандартов}

Все применимые международные, национальные и/или институциональные принципы ухода и использования животных были соблюдены.

\section{Конфликт интересов}

Авторы заявляют, что у них нет конфликта интересов.

\section{Список литературы}

[1] World Health Organization, International Agency for Research on Cancer. IARC. Non-ionizing radiation, Part 1: static and extremely low-frequency (ELF) electric and magnetic fields, IARC monographs on the evaluation of carcinogenic risks to humans. 2002. Vol. 80. P. 1-395.

[2] Pavon-Carrasco F.J., De Santis A. // Frontiers in Earth Science. 2016. Vol. 4. id. 40. DOI: 10.3389/feart.2016.00040

[3] Anderson P.C., Rich F.J., Borisov S. // J. Atmospheric and Solar-Terrestrial Phys. 2018. Vol. 177. P. 237-246. DOI: 10.1016/j.jastp.2018.03.015

[4] Стеббанов В.Е., Щеголев Б.Ф., Крячко О.В., Кузьменко Н.В., Сурма С.В., Спивак И.М. // ДАН. 2015. Т. 461. № 4. C. 485-488. DOI: 10.7868/S0869565215100291

[5] Surma S.V., Belostotskaya G.B., Shchegolev B.F., Stefanov V.E. // Bioelectromagnetics. 2014. Vol. 35. P. 537-546. DOI: $10.1002 /$ bem.21876 
[6] Никитина Е.А., Медведева А.В., Герасименко М.С., Проников В.С., Сурма С.В., Щеголев Б.Ф., СавватееваПопова E.B. // Журнал высшей нервной деятельности им. И.П. Павлова. 2017. Т. 67. № 2. С. 246256. DOI: 10.7868/S0044467717020101 [Nikitina E.A., Medvedeva A.V., Gerasimenko M.S., Pronikov V.S., Surma S.V., Shchegolev B.F., Savvateeva-Popova E.V. Neuroscience and Behavioral Physiology. 2018. Vol. 48. N 7. P. 796-803. DOI: $10.1007 / \mathrm{s} 11055-018-0632-2]$

[7] Хавинсон В.Х., Кузник Б.И., Рызкак Г.А. Пептидные геропротекторы - эпигенетические регуляторы физиологических функций организма. СПб.: Изд-во РГПУ им. А.И. Герцена, 2014. $271 \mathrm{c}$.

[8] Вахитов Т.Я., Чалисова Н.И., Балыкина Н.А., Петров Л.Н., Ноздрачев А.Д. // ДАН. 2009. Т. 428. № 1. С. $121-$ 124.

[7] Чалисова Н.И., Концевая Е.А., Войщеховская М.А., Комашня А.B. // Успехи геронтологии. 2011. Т. 24. № 2. C. $189-199$.

[9] Никитина Е.А., Токмачева Е.В., СавватееваПопова Е.В. // Генетика. 2003. Т. 39. № 1. С. 33-40. [Nikitina E.A., Tokmatcheva E.V., Savvateeva-Popova E.V. // Russ. J. Genetics. 2003. Vol. 39. N 1. P. 25-31.]

[10] Kamyshev N.G., Iliadi K.G., Bragina J.V. // Learn. Mem. 1999. Vol. 6. N 1. P. 1-20.

[12] Иванова П.Н., Сурма С.В., Щеголев Б.Ф., Чалисова Н.И., Захаров Г.А., Никитина Е.А., Ноздрачев А.Д. // ДАН. 2018. Т. 481. № 4. С. 459-461. DOI: $10.31857 / \mathrm{S} 086956520001756-4$

[Ivanova P.N., Surma S.V., Shchegolev B.F., Chalisova N.I., Zakharov G.A., Nikitina E.A., Nozdrachev A.D. // Dokl. Biolog. Sciebces. 2018. Vol. 481. N 1. P. 132-134. DOI: $10.1134 / \mathrm{S} 0012496618040075]$

[13] Савватеева-Попова Е.В., Никитина Е.А., Медведева A.B. // Генетика. Т. 51. № 5. С. 613-624. DOI: 10.7868/S0016675815050070 [Savvateeva-Popova E.V., Medvedeva A.V., Nikitina E.A. // Russ. J. Genetics. 2015. Vol. 51. N 5. P. 518-528. DOI: 10.1134/S1022795415050075]

[14] Shoki O., Nobuyoshi N., Hiroshi S., Hiroshi K. // J. Neurochem. 1998. Vol. 70. N 1. P. 299-307. doi.org/10.1046/j.1471-4159.1998.70010299.x

[15] Чалисова Н.И., Лопатина Н.Г., Камышев Н.Г., Зачепило Т.Г., Козина Л.С., Заломаева Е.С. // Успехи геронтологии. 2017. Т. 30. № 6. С. 82.

[16] Чалисова Н.И., Иванова П.Н., Заломаева Е.С., Никитина Е.А., Козина Л.С. // Успехи геронтологии. 2018. T. 31. № 5. C. 732-736. [Chalisova N.I., Ivanova P.N., Zalomaeva E.S., Nikitina E.A., Kosina L.S. // Adv. Gerontology. 2019. Vol. 9. N 2. P. 186-189.]

[17] Елдашев И.С., Щеголев Б.Ф., Сурма С.В., Белостоикая Г.Б. // Биофизика. 2010. Т. 55. № 5. C. 868-874. [Eldashev I.S., Shchegolev B.F., Surma S.V., Belostotskaya G.B. // Biophysics. 2010. Vol. 55. N 5. P. 765770.]

[18] Никитина Е.А., Черникова Д.А., Васильева О.В., журавлев А.В., Медведева А.В, Домнина Н.С., Сергеева О.Ю., Вольева В.Б., Щеголев Б.Ф., СавватееваПопова Е.В. // Биотехнология. 2018. Т. 34. № 3. С. 67-77. DOI: 10.21519/0234-2758-2018-34-3-67-77 [Nikitina E.A., Chernikova D.A., Vasilyeva O.V., Zhuravlev A.V., Medvedeva A.V., Domnina N.S., Sergeeva O.Yu., Vol'eva V.B., Shchegolev B.F., Savvateeva-Popova E.V. // Biotechnology in Russia. 2018. Vol. 34. N 3. P. 67-77.

[19] Бучаченко А.Л. // Успехи химии. 2014. Т. 83. № 1. С. 1-12. [Buchachenko A.L. // Russ. Chem. Rev. 2014. Vol. 83. N 1. P. 1-12.] 